\title{
Cerebrospinal Anandamide Levels are Elevated in Acute Schizophrenia and are Inversely Correlated with Psychotic Symptoms
}

\author{
Andrea Giuffrida ${ }^{1,3,4}$, F Markus Leweke ${ }^{2,3}$, Christoph W Gerth ${ }^{2}$, Daniela Schreiber ${ }^{1,2}$, Dagmar Koethe ${ }^{2}$, \\ Johannes Faulhaber ${ }^{2}$, Joachim Klosterkötter ${ }^{2}$ and Daniele Piomelli*, I \\ 'Department of Pharmacology, University of California, Irvine, CA, USA; 2 Department of Psychiatry and Psychotherapy, University of Cologne, \\ Cologne, Germany
}

\begin{abstract}
The endocannabinoids are a family of bioactive lipids that activate $C B_{1}$ cannabinoid receptors in the brain and exert intense emotional and cognitive effects. Here, we have examined the role of endocannabinoid signaling in psychotic states by measuring levels of the endocannabinoid anandamide in cerebrospinal fluid (CSF) of acute paranoid-type schizophrenic patients. We found that CSF anandamide levels are eight-fold higher in antipsychotic-naïve first-episode paranoid schizophrenics $(n=47)$ than healthy controls $(n=84)$, dementia patients $(n=13)$ or affective disorder patients $(n=22)$. Such an alteration is absent in schizophrenics treated with 'typical' antipsychotics $(n=37)$, which antagonize dopamine $D_{2}$-like receptors, but not in those treated with 'atypical' antipsychotics $(n=34)$, which preferentially antagonize $5 \mathrm{HT}_{2 \mathrm{~A}}$ receptors. Furthermore, we found that, in nonmedicated acute schizophrenics, CSF anandamide is negatively correlated with psychotic symptoms $\left(r_{S}=-0.452, P=0.00 \mathrm{I}\right)$. The results suggest that anandamide elevation in acute paranoid schizophrenia may reflect a compensatory adaptation to the disease state.

Neuropsychopharmacology (2004) 29, 2 I08-2II4, advance online publication, 8 September 2004; doi: I 0.1038/sj.npp. I 300558
\end{abstract}

Keywords: cannabinoids; anandamide; antipsychotic; dopamine

\section{INTRODUCTION}

Cannabis use is frequent among schizophrenic patients (Kovasznay et al, 1997) and is suspected to precipitate psychotic symptoms in vulnerable subjects (Andréasson et al, 1987; Linszen et al, 1994). This finding, the observation that psychoactive cannabinoids cause perceptual alterations that are reminiscent of those observed in schizophrenia (Leweke et al, 1999a; Semple et al, 2003), and the association of a $\mathrm{CB}_{1}$ cannabinoid receptor polymorphism with hebephrenic schizophrenia (Ujike et al, 2002) suggest a link between psychoses and hyperactivity of the endogenous cannabinoid system in the brain (Emrich et al, 1997). This signaling system consists of naturally occurring

\footnotetext{
* Correspondence: Professor D Piomelli, Department of Pharmacology, University of California, Irvine, Irvine, CA 92697-4625, USA, Tel: + I 949824 6180, Fax: + I 949824 6305, E-mail: piomelli@uci.edu

${ }^{3}$ These authors contributed equally to this work

${ }^{4}$ Current address: Department of Pharmacology, University of Texas Health Science Center, San Antonio, TX 78229, USA

Received 7 January 2004; revised 7 April 2004; accepted I 5 June 2004 Online publication: 3 August 2004 at http://www.acnp.org/citations/ Npp08030404008/default.pdf
}

endocannabinoid lipids - of which anandamide (Devane et al, 1992; Di Marzo et al, 1994) is the first characterized example - and their attending $\mathrm{CB}_{1}$ cannabinoid receptors, which are expressed in brain areas involved in the control of motor functions, cognition, and motivation (Herkenham et al, 1990; Matsuda et al, 1993; Glass et al, 1997; Piomelli 2003).

The hypothesis that a dysfunction in endocannabinoid signaling may be associated with schizophrenia is further supported by studies showing that endocannabinoid levels in cerebrospinal fluid (CSF) (Leweke et al, 1999b) and plasma (Yao et al, 2002; De Marchi et al, 2003) as well as $\mathrm{CB}_{1}$ receptor expression (Dean et al, 2001) are abnormal in schizophrenic patients. The interpretation of these results is obscured, however, by the small number of subjects involved, the interference of concurrent drug therapy, and the lack of systematic comparison with other mental disorders in which endocannabinoid signaling also might be dysregulated. Here, we show that the CSF levels of the endocannabinoid anandamide are profoundly and selectively elevated in paranoid-type schizophrenia, negatively correlate with the psychotic symptoms of this disease, and are normalized by treatment with 'typical' but not 'atypical' antipsychotic drugs. 


\section{Subjects and Methods}

The Ethical committee of the Medical Faculty of the University of Cologne and the Internal Review Board of the University of California, Irvine reviewed and approved the protocol of this study and the procedures for sample collection and analysis. All study participants gave their written informed consent. All clinical investigations were conducted according to the principles expressed in the Declaration of Helsinki.

Study outline and primary hypothesis. Psychiatric inpatients and healthy volunteers were enrolled into this study following a given protocol. This was planned to test the hypothesis that endogenous cannabinoids in CSF and/or serum are altered in patients suffering from schizophreniaspectrum disorders, but not from other psychiatric disorders, when compared to healthy controls. The concentrations of anandamide were the primary end point of the study. Two noncannabinoid analogs of anandamide, palmitoylethanolamide (PEA) and oleoylethanolamide (OEA), were also measured.

Subjects. Healthy volunteers served as controls and were recruited by word of mouth in the catchment area of the Department of Psychiatry and Psychotherapy of the University of Cologne. They were gathered for this particular study only and received an allowance for their participation in the study. Healthy volunteers were screened for psychiatric disorders using the SCID-I and the SCID-II clinical interview. Neurological and physical examination was carried out by a trained neurologist and was found normal in all cases. Any current medication other than oral contraceptives and hormone substitution was not accepted in healthy volunteers. A negative family history for psychiatric and neurological disorders as well as a negative urine drug screening for illicit drugs were also required. Previous use of illicit drugs other than cannabis was not allowed in healthy volunteers. Cannabis use was quantified retrospectively with respect to the frequency of cannabis use in lifetime. In all, 57 volunteers were selected with a lifetime frequency of cannabis use of up to five times, but not within the last 12 months before inclusion into the study. The remaining 27 volunteers showed a lifetime cannabis use of 20 to 50 times but not within the last 6 months prior to the study. Both groups were matched for age and gender. Thus, the group of healthy controls showed a number of frequent cannabis users close to those in the groups of schizophrenic patients.

Schizophrenic and nonschizophrenic patients fulfilled pertinent diagnostic criteria, as defined by the IV edition of the Diagnostic and Statistical Manual (DSM-IV) (American Psychiatric Association, 1994). All patients received lumbar punctures within the routine diagnostic process, as recommended by the German Society of Psychiatry and Psychotherapy (DGPPN). In all, 38 first episode (first-time clinical diagnosis) antipsychotic-naïve (no previous or current treatment with antipsychotic/neuroleptic medication to the best of our knowledge, tranquilizers were allowed) schizophrenics met DSM-IV criteria for paranoid schizophrenia (295.30), while nine additional antipsychotic-naïve patients met DSM-IV criteria for schizophreniform psychosis (295.40) due to duration of illness. A total of 12 depressed patients met DSM-IV criteria for single episode depression (296.2), four met DSM-IV criteria for recurrent episodes depression (296.3), four met DSM-IV criteria for bipolar depression (296.5), and two met DSM-IV criteria for bipolar mania (296.4). In all, 11 patients affected by dementia met DSM-IV criteria for Alzheimer dementia (290.0-290.4) and two met DSM-IV criteria for vascular dementia (290.4). All depressed patients received pharmacological treatment, which included selective serotonin-reuptake inhibitors $(n=7)$, selective noradrenaline-reuptake inhibitors $(n=3)$, noradrenaline-reuptake inhibitors $(n=3)$, lithium $(n=3)$, benzodiazepines $(n=15)$, and low-dose antipsychotics $(n=5)$. Dementia patients also received pharmacological treatment, which included melperon $(n=5)$ risperidone $(n=3)$, serotonin-reuptake inhibitors $(n=3)$, and cholinesterase inhibitors $(n=1)$. Trained clinical psychiatrists evaluated ongoing psychotic symptoms in schizophrenic patients on the day of lumbar puncture using the Positive and Negative Syndrome Scale (PANSS) (Kay et al, 1987).

CSF investigations. CSF samples were collected at approximately 1200 using a nontraumatic lumbar puncture procedure. Routine CSF analyses included total cell count, total protein, CSF/serum albumin and IgG quotients, and determination of oligoclonal bands by isoelectric focusing and silver staining. Extensive virological and microbiological testing of the CSF was also performed. All CSF samples revealed normal cell counts, normal CSF/serum albumin ratios, and no oligoclonal bands, indicating healthy bloodbrain barrier function and lack of intrathecal immunoglobulin $\mathrm{G}$ synthesis.

To quantify fatty acid ethanolamides, aliquots $(1 \mathrm{ml})$ from CSF samples (total volume, $15-20 \mathrm{ml}$ ) were spiked with $25 \mathrm{pmol}$ of $\left[{ }^{2} \mathrm{H}_{4}\right]$ anandamide, $\left[{ }^{2} \mathrm{H}_{4}\right] \mathrm{PEA}$, and $\left[{ }^{2} \mathrm{H}_{4}\right] \mathrm{OEA}$, (internal standards) and subjected to acetone precipitation of protein. The supernatants were collected and their volumes reduced under a stream of nitrogen. Lipids were extracted with chloroform/methanol (2:1 ( $\mathrm{vol} / \mathrm{vol}))$, and chloroform phases were evaporated to dryness under nitrogen and reconstituted in methanol and chloroform $(80 \mu \mathrm{l}$ total). Fatty acid ethanolamides were purified and quantified by isotope dilution high-performance liquid chromatography/mass spectrometry (HPLC/MS) (Giuffrida et al, 2000) using an HP 1100 Series HPLC/MS system equipped with an octadecylsilica Hypersil column $\left(100 \times 4.6 \mathrm{~mm}^{2}\right.$, i.d. $\left.5 \mu \mathrm{m}\right)$ (Agilent Technologies). MS analyses were performed with an electrospray ion source as described previously (Giuffrida et al, 2000). Lowest limits of detection were $0.3 \mathrm{pmol} / \mathrm{sample}$ for anandamide and $0.1 \mathrm{pmol} / \mathrm{sample}$ for PEA and OEA (Giuffrida et al, 2000).

Chemicals. Fatty acyl chlorides (5,8,11,14-eicosatetraenoylchloride, hexadecanoylchloride and 9-cis-octadecenoylchloride) were from Nu-Check Prep (Elysian, MN); ${ }^{2} \mathrm{H}_{4}$-labeled ethanolamine (isotopic atom enrichment $=98 \%$ ) was from Cambridge Isotope Laboratories (Andover, MA). All other drugs were from Sigma-Aldrich (St Louis, MO). All solvents were from Burdick and Jackson (Muskegon, MI). 
Statistical analyses. Statistical analyses were performed using SPSS 11.0 for Macintosh. Nonparametric statistical tests were performed for detection of overall effects and subsequent paired comparisons in all cases. These nonparametric tests were selected for an appropriate statistical approach to avoid influences of the distribution of the data on our statistical analyses. Data were analyzed using the Kruskal-Wallis test corrected for ties and followed by twotailed Mann-Whitney tie-corrected tests. A Bonferroni correction was applied to correct for multiple comparisons of the primary end point. Correlations between data sets were calculated by use of a nonparametric tie-corrected Spearman's rank correlation. The particular implementation of this statistical method in SPSS 11 also addresses a potentially larger proportion of ties (see SPSS 11 documentation).

\section{RESULTS}

We recruited a cohort of 237 subjects, which comprised 84 healthy volunteers with no family history of schizophrenia or other detectable medical, psychiatric or neurological disturbances, or history (53.6\% male; age $27.9 \pm 5.8$ years); 47 antipsychotic-naïve first episode paranoid schizophrenics $(72.3 \%$ male; age $28.9 \pm 9.0$ years); 71 acute paranoid schizophrenics treated with antipsychotic medications ( $80.3 \%$ male; age $29.1 \pm 10.1$ years); 13 dementia patients (46.2\% male; age $77.8 \pm 7.8$ years); and 22 affective disorder patients (54.5\% male; age $44.7 \pm 15.8$ years). Antipsychotics were either 'typical' $\left(D_{2}\right.$ antagonistic: haloperidol, $n=18$; flupentixol, $n=1$; phenothiazines, $n=7$ (perazine, $n=4$; perphenazine, $n=1$; levomepromazine, $n=1$ ); amisulpride, $n=11 ; 86.5 \%$ male; age $29.3 \pm 10.5$ years) or 'atypical' $\left(5 \mathrm{HT}_{2 \mathrm{~A}} / \mathrm{D}_{2}\right.$ antagonistic: risperidone, $n=14$; clozapine-like, $n=21$ (clozapine, $n=2$; olanzapine, $n=15$; quetiapine, $n=4) ; 73.5 \%$ male; age $29.0 \pm 9.8$ years). In all subjects, we measured CSF and serum levels of endogenous anandamide along with PEA and OEA, two endogenous fatty acid ethanolamides that are biogenetically related to anandamide, but do not activate $\mathrm{CB}_{1}$ receptors (Calignano et al, 1998; Rodríguez de Fonseca et al, 2001; Fu et al, 2003).

In healthy volunteers, the concentrations of anandamide were $0.007 \pm 0.002 \mathrm{pmol} / \mathrm{ml}$ (mean value $(\mathrm{MV}) \pm$ standard error of the mean (SEM)) in CSF $(n=81)$ and $0.427 \pm 0.071 \mathrm{pmol} / \mathrm{ml}$ in serum $(n=81)$. There was no significant correlation between anandamide concentrations in the two compartments (Spearman's, $r_{\mathrm{S}}=0.033, P=0.768$, $n=81$ ). This was also the case for all groups of patients, but the group of schizophrenics treated with 'typical' antipsychotics where a significant correlation between both compartments was found (Spearman's, $r_{\mathrm{S}}=0.474, P=0.004$ $n=35$ ). However, there was no significant correlation between anandamide concentrations both in CSF and serum and age in healthy controls (Spearman's, $r_{\mathrm{S}}=0.030$, $P=0.790, n=81$ ) or any group of patients. There was also no significant difference of CSF anandamide for gender in healthy controls $(P=0.742$, Mann-Whitney test) as well as any group of patients.

Anandamide levels were on average eight times higher in the CSF of antipsychotic-naive acute schizophrenics than healthy controls $(0.057 \pm 0.011 \mathrm{pmol} / \mathrm{ml}, \quad n=47$,

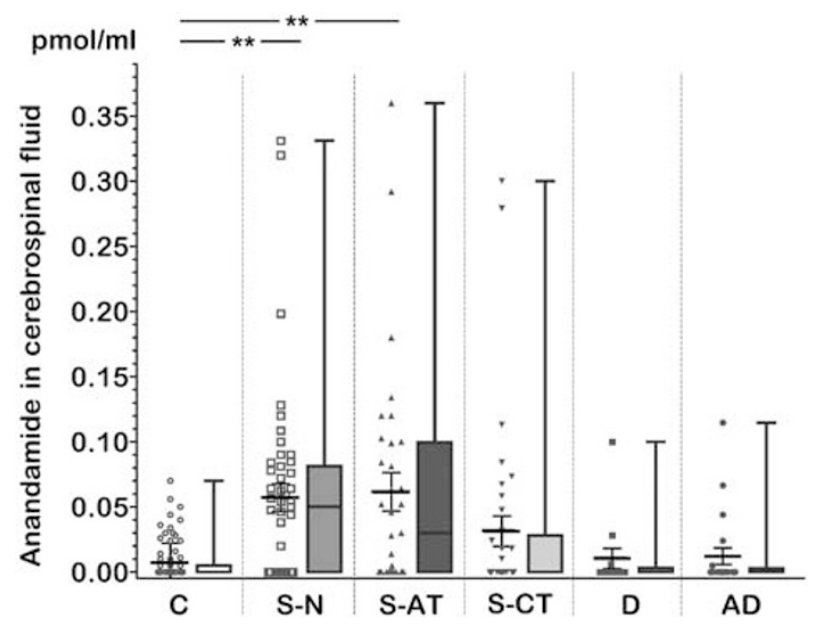

Figure I Anandamide levels are elevated in the CSF of antipsychoticfree first-episode schizophrenic patients. CSF anandamide in healthy volunteers (C); antipsychotic-free schizophrenics with paranoid schizophrenia (S-N); acute schizophrenics (paranoid type) treated with 'atypical' (S-AT) or 'typical' (S-CT) antipsychotic drugs; and patients affected by dementia (D) or affective disorders (AD) without psychotic symptoms. Single values are given with mean \pm SEM as well as corresponding box-plots illustrating median, range, and quartiles for each group. Statistically significant differences between groups are shown (*P $P \leqslant 0.01$; ** $P \leqslant 0.00$ I; Kruskal-Wallis test followed by Mann-Whitney test; a Bonferroni correction (five tests) of the $\alpha$-level was applied: $\alpha=0.05 / 5=0.0$ I).

$P=0.000$, Kruskal-Wallis test followed by Mann-Whitney test) (Figure 1a). No such elevation in CSF anandamide was observed in patients affected by dementia or affective disorders (Figure 1a). Likewise, no elevation of anandamide was observed in serum (controls, $0.427 \pm 0.071 \mathrm{pmol} / \mathrm{ml}, n=81$; antipsychotic-naïve schizophrenics, $0.651 \pm 0.140 \mathrm{pmol} / \mathrm{ml}, n=43, P=0.380$, KruskalWallis test).

Schizophrenics treated with 'atypical' antipsychotic drugs had CSF anandamide levels $(0.062 \pm 0.016 \mathrm{pmol} / \mathrm{ml}, n=31)$ comparable to those of antipsychotic-naïve schizophrenics (Figure 1a) and significantly different from those measured in healthy controls $(P=0.000$, Kruskal-Wallis followed by Mann-Whitney test). On the other hand, CSF anandamide levels in schizophrenics receiving 'typical' antipsychotics were not different from controls $(0.031 \pm 0.012 \mathrm{pmol} / \mathrm{ml}$, $n=36, \quad P=0.298$; Kruskal-Wallis followed by MannWhitney test). Interestingly, patients treated with risperidone $(n=11)$, which is known to antagonize $\mathrm{D}_{2}$-like dopamine receptors more effectively than other 'atypical' antipsychotics, showed slightly lower CSF anandamide levels $(0.043 \pm 0.014 \mathrm{pmol} / \mathrm{ml})$ than those treated with clozapine-like drugs $(0.072 \pm 0.023 \mathrm{pmol} / \mathrm{ml}, n=20)$. This difference was, however, not statistically underlined $(P=0.792$, Mann-Whitney test $)$ and its relevance, if any, remains unclear.

In contrast to the elevation observed with anandamide, CSF levels of OEA were identical in antipsychotic-naïve schizophrenics and control subjects (controls, 1.011士 $0.136 \mathrm{pmol} / \mathrm{ml}, n=81$; antipsychotic-naïve schizophrenics, $1.116 \pm 0.217 \mathrm{pmol} / \mathrm{ml}, n=37, P=0.624$, Kruskal-Wallis test), while CSF levels of PEA were lower in antipsychotic-naïve 
schizophrenics (controls, $5.282 \pm 0.554 \mathrm{pmol} / \mathrm{ml}, \quad n=81$; antipsychotic-naïve schizophrenics, $3.441 \pm 0.494, n=45$, $P=0.017)$. Compared to antipsychotic-naïve schizophrenics and controls, patients treated with 'atypical' antipsychotics showed slightly elevated CSF PEA $(5.447 \pm 1.820 \mathrm{pmol} / \mathrm{ml}$, $n=27$ ) while those treated with 'typical' antipsychotics did not $(3.008 \pm 0.480 \mathrm{pmol} / \mathrm{ml}, n=32)$. This difference was, however, statistically insignificant $(P=0.086)$. No correlation to age and no significant differences for gender were found for anandamide, PEA, or OEA in nonparametric correlation and a two-sample test, respectively.

Previous studies have suggested that anandamide release in the brain may serve as an inhibitory feedback signal countering dopamine activation of motor behavior (Giuffrida et al, 1999; Beltramo et al, 2000). We hypothesized therefore that anandamide might also serve as a homeostatic function in acute schizophrenia, in which exaggerated dopaminergic transmission has been documented (AbiDargham et al, 2000; Meyer-Lindenberg et al, 2002). As an initial test of this idea, we examined the correlation between CSF levels of anandamide and psychotic symptoms. These include positive symptoms (eg delusions and hallucinations) as well as negative symptoms (apathy, paucity of speech, blunting, or incongruity of emotional responses) and more general psychopathological features (eg depressive mood or aggression) (DSM-IV). In agreement with our hypothesis, we found that, in antipsychotic-naïve schizophrenics, CSF anandamide levels were negatively correlated with PANSS scores (PANSS-T: cumulative value for all symptom complexes; PANSS-P: positive symptoms; PANSS$\mathrm{N}$ : negative symptoms; and PANSS-G: general symptoms) (Figure 2) (PANSS-T: $r_{\mathrm{S}}=-0.452, P=0.001$; PANSS-P: $r_{\mathrm{S}}=-0.347 ; P=0.017 ;$ PANSS-N: $r_{\mathrm{S}}=-0.409, P=0.004 ;$ PANSS-G: $\left.r_{\mathrm{S}}=-0.426, P=0.003 ; n=47\right)$. Although the nonparametric Spearman's tie-corrected rank correlation is quite robust for outliers, we performed a sensitivity analysis to rule out potential effects of the three highest values of CSF anandamide on its correlation to psychopathology (Figure 3). This sensitivity analysis revealed that statistical significance of the correlations for PANSS-T, PANSS-N, and PANSS-G was maintained even when the three highest values of CSF anandamide were removed from the analysis (PANSS-T: $r_{\mathrm{S}}=-0.401, P=0.007$; PANSS-P: $r_{\mathrm{S}}=-0.260$; $P=0.088 ; \quad$ PANSS-N: $r_{\mathrm{S}}=-0.341, \quad P=0.023$; PANSS-G: $\left.r_{\mathrm{S}}=-0.401, P=0.007 ; n=44\right)$. It is noteworthy that the history of cannabis use in the group of healthy controls and antipsychotic-naïve schizophrenics was comparable to some extent and no overall effect of cannabis use on the primary end point of this study was observed.

\section{DISCUSSION}

We found that the CSF levels of anandamide are markedly elevated in neuroleptic-naïve acute schizophrenic patients. This finding may be relevant, for three reasons, to the pathology of schizophrenia. First, the change in anandamide levels was presumably of central origin, because no such change was observed in serum. In this regard, our results differ from those of De Marchi et al (2003), who reported increased levels of anandamide in whole blood of schizophrenics. This discrepancy might be due to a Schizophrenia - antipsychotic-naïve Anandamide in CSF to PANSS T

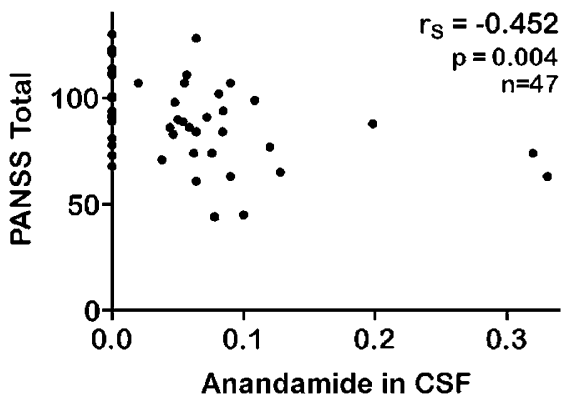

b Schizophrenia - antipsychotic-naïve Anandamide in CSF to PANSS $P$

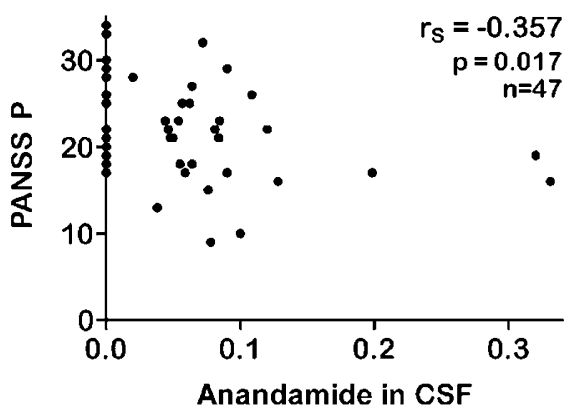

C Schizophrenia - antipsychotic-naïve Anandamide in CSF to PANSS N

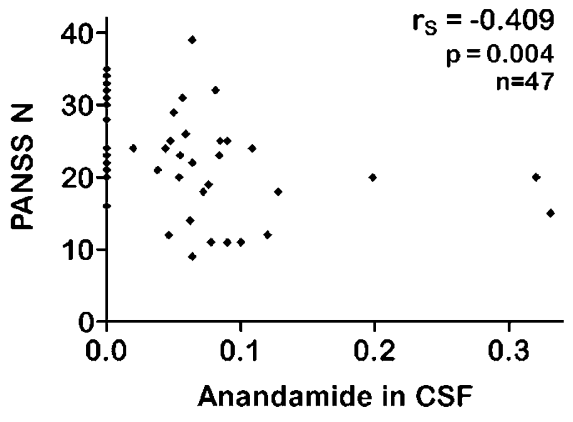

d Schizophrenia - antipsychotic-naïve Anandamide in CSF to PANSS G

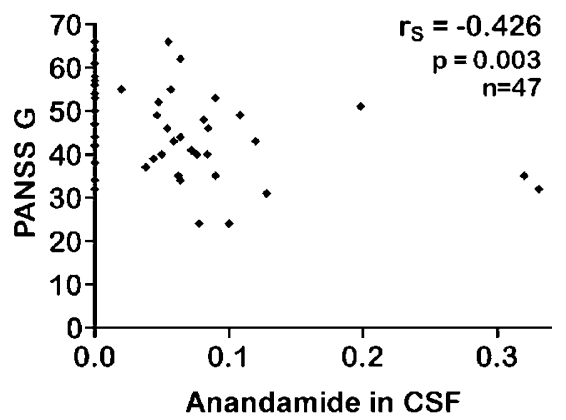

Figure 2 Correlations between CSF anandamide levels and psychotic symptoms. CSF anandamide levels in first-episode, antipsychotic-naïve schizophrenics (paranoid type) are negatively correlated with PANSS scores: (a) cumulative value for all symptom complexes (PANSS-T); (b) positive psychotic symptoms (PANSS-P); (c) negative psychotic symptoms (PANSS-N); and (d) general psychotic symptoms (PANSS-G). 
differences in experimental procedures between the studies (eg whole blood $v s$ serum) or to the small number of patients investigated by De Marchi et al $(n=12)$. Second,

a

Schizophrenia - antipsychotic-naïve Anandamide in CSF to PANSS T Sensitivity-analysis

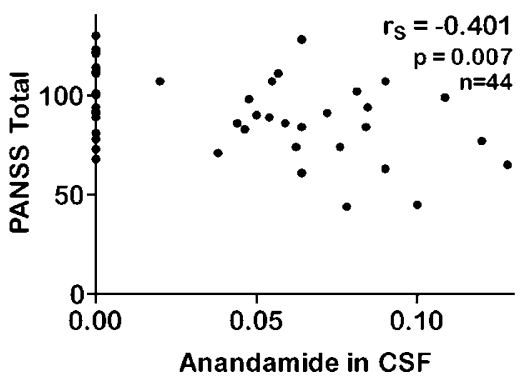

b Schizophrenia - antipsychotic-naïve Anandamide in CSF to PANSS $P$ Sensitivity-analysis

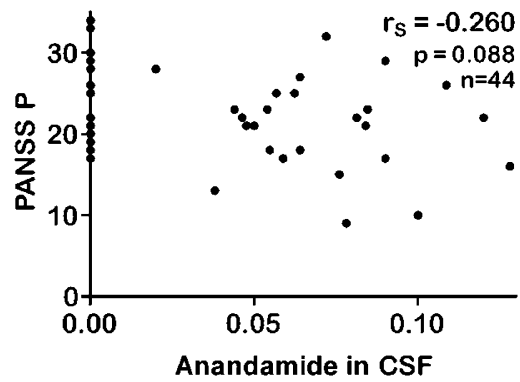

C Schizophrenia - antipsychotic-naïve Anandamide in CSF to PANSS N Sensitivity-analysis

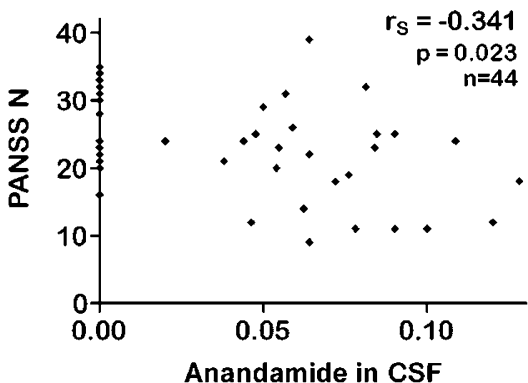

d Schizophrenia - antipsychotic-naïve Anandamide in CSF to PANSS G Sensitivity-analysis

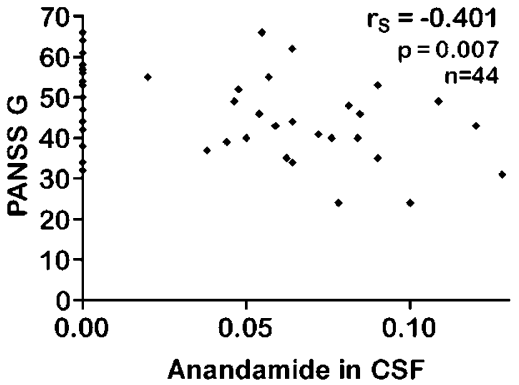

the elevation in anandamide concentration was unlikely to be caused by a generalized alteration in lipid signaling, which is hypothesized to occur in schizophrenia (Horrobin 1998), because the levels of two closely related analogs of anandamide, OEA and PEA, were not increased in schizophrenics. It is noteworthy that we found that PEA levels in antipsychotic-naïve schizophrenics were lower than controls, thus correcting an earlier study from our lab, which reported elevated PEA levels in the CSF of a small set $(n=11)$ of treated and untreated schizophrenics (Leweke et al, 1999b). Third, the elevation in CSF anandamide was apparently restricted to schizophrenia, because it was not found in patients affected by dementia or affective disorders.

An additional finding of the present study, which was not a primary end point of our analyses but a result of a subsequent explorative approach, is that schizophrenic patients treated with 'typical' antipsychotics (drugs that antagonize the actions of dopamine at $\mathrm{D}_{2}$-like receptors) had CSF anandamide levels similar to those of healthy subjects, whereas patients treated with 'atypical' antipsychotics (which preferentially interact with serotonin $5-\mathrm{HT}_{2 \mathrm{~A}}$ receptors) (Meltzer, 1999) had levels similar to those of drug-naïve schizophrenics. This result is consistent with animal studies, which show that activation of dopamine $\mathrm{D}_{2}$ like receptors initiates anandamide synthesis in limbic and motor areas of the rat brain (Giuffrida et al, 1999; Ferrer et al, 2003), and suggests that 'typical' antipsychotics normalize anandamide levels by blocking $\mathrm{D}_{2}$-like receptors. We cannot exclude, however, the possibility that antagonistic actions at other receptors targeted by these drugs (eg adrenergic, histaminergic, etc) also might be involved.

What, if any, are the functional consequences of elevated anandamidergic activity in the schizophrenic brain? Pharmacological experiments in the rat have suggested that anandamide release may serve as an inhibitory feedback signal countering dopamine activation of motor behavior (Giuffrida et al, 1999; Beltramo et al, 2000). The negative correlation of CSF anandamide with psychopathological symptoms in acute, antipsychotic-naïve paranoid schizophrenics suggests that anandamide might play a similar adaptive role in acute schizophrenia. This hypothesis will require, however, further test. In this context, it is important to point out results from a Phase III clinical trial, which suggests that the $\mathrm{CB}_{1}$ antagonist rimonabant (SR141716A) has no therapeutic effect in schizophrenia and schizoaffective disorders (Arvanitis et al, 2002).

Heavy cannabis use is considered a risk factor for the clinical manifestation of schizophrenia and might promote psychotic episodes in vulnerable individuals (Andréasson et al, 1987; Arseneault et al, 2002; Linszen et al, 1994). How

Figure 3 Sensitivity analysis for the correlations between CSF anandamide levels and psychotic symptoms (see also Figure 2). CSF anandamide levels in first-episode, antipsychotic-naïve schizophrenics (paranoid type) remain negatively correlated with PANSS-T, PANSS-N, and PANSS-G scores. (a) Cumulative value for all symptom complexes (PANSS-T); (b) positive psychotic symptoms (PANSS-P); (c) negative psychotic symptoms (PANSS-N); and (d) general psychotic symptoms (PANSS-G). 
do these clinical observations relate to the present findings? One possibility is that heavy cannabis abuse may lead to desensitization of brain $\mathrm{CB}_{1}$ receptors, which may in turn facilitate psychoses. This hypothesis needs to be tested in humans, but is supported by animal studies showing that $\mathrm{CB}_{1}$ receptors undergo rapid desensitization in vivo (SimSelley and Martin, 2002) and that $\Delta^{9}$-THC antagonizes Damphetamine-induced stereotypies in naïve rats, but not in animals made cannabinoid tolerant by repeated $\Delta^{9}$-THC injections (Gorriti et al, 1999). Support to this hypothesis also comes from a single-case clinical study, which suggests that the worsening of psychotic manifestations associated with cannabis intoxication lags several hours behind the mood-elevating and anxiolytic effects of the drug (Voruganti et al, 2001). Irrespective of these speculations, our findings confirm the existence of an anandamidergic dysregulation in schizophrenia and underline the need for further investigation on the role for this endocannabinoid lipid in psychotic states.

\section{ACKNOWLEDGEMENTS}

This study was supported by NARSAD (Staglin Family Vineyard Musical Fellowship to DP), the Center for Medicinal Cannabis Research of the University of California (to DP), the Stanley Medical Research Institute (01-315 to FML), and the Koeln Fortune Program (108-2000 to FML). We thank Dr ML Solbrig for reading the manuscript critically and Professor W Lehmacher for advice on statistical analysis.

\section{REFERENCES}

Abi-Dargham A, Rodenhiser J, Printz D, Zea-Ponce Y, Gil R, Kegeles LS et al (2000). Increased baseline occupancy of D2 receptors by dopamine in schizophrenia. Proc Natl Acad Sci USA 97: 8104-8109.

Andréasson S, Allebeck P, Engström A, Rydberg U (1987). Cannabis and schizophrenia. Lancet 2: 1483-1486.

Arseneault L, Cannon M, Poulton R, Murray R, Caspi A, Moffitt TE (2002). Cannabis use in adolescence and risk for adult psychosis: longitudinal prospective study. BMJ 325: 1212-1213.

Arvanitis L, Bauer D, Rein W (2002). Results of the metatrial project: efficacy and tolerability of four novel compounds in schizophrenia and schizoaffective disorder. Int J Neuropsychopharmacol 5: S188.

American Psychiatric Association (1994). Diagnostic and Statistical Manual of Mental Disorders, 4th DMS-IV edn. American Psychiatric Press Inc.: Washington, DC.

Beltramo M, Rodriguez de Fonseca F, Navarro M, Calignano A, Gorriti MA, Grammatikopoulos G et al (2000). Reversal of dopamine $\mathrm{D}_{2}$-receptor responses by an anandamide transport inhibitor. J Neurosci 20: 3401-3407.

Calignano A, La Rana G, Giuffrida A, Piomelli D (1998). Control of pain initiation by endogenous cannabinoids. Nature 394: 277-281.

Dean B, Sundram S, Bradbury R, Scarr E, Copolov D (2001). Studies on $\left[{ }^{3} \mathrm{H}\right] \mathrm{CP}-55940$ binding in the human central nervous system: regional specific changes in density of cannabinoid-1 receptors associated with schizophrenia and cannabis use. Neuroscience 103: 9-15.

De Marchi N, De Petrocellis L, Orlando P, Daniele F, Fezza F, Di Marzo V (2003). Endocannabinoid signaling in the blood of patients with schizophrenia. Lipids Health Dis 2: 5.
Devane W, Hanus L, Breuer A, Pertwee R, Stevenson L, Griffin $G$ et al (1992). Isolation and structure of a brain constituent that binds to the cannabinoid receptor. Science 258: 1946-1949.

Di Marzo V, Fontana A, Cadas H, Schinelli S, Cimino G, Schwartz $\mathrm{J}-\mathrm{C}$ et al (1994). Formation and inactivation of endogenous cannabinoid anandamide in central neurons. Nature 372: 686-691.

Emrich HM, Leweke FM, Schneider U (1997). Towards a cannabinoid hypothesis of schizophrenia: cognitive impairments due to dysregulation of the endogenous cannabinoid system. Pharmacol Biochem Behav 56: 803-807.

Ferrer B, Asbrock N, Kathuria S, Piomelli D, Giuffrida A (2003). Effects of levodopa onendocannabinoid levels in rat basal ganglia: implications for the treatment of levodopa-induced dyskinesias. Eur J Neurosci 18: 1607-1614.

Fu J, Gaetani S, Oveisi F, Loverme J, Serrano A, Rodriguez de Fonseca F et al (2003). Oleylethanolamide regulates feeding and body weight through activation of PPAR- $\alpha$. Nature 425: 90-93.

Giuffrida A, Parsons LH, Kerr TM, Rodríguez de Fonseca F, Navarro M, Piomelli D (1999). Dopamine activation of endogenous cannabinoid signaling in dorsal striatum. Nat Neurosci 2: 358-363.

Giuffrida A, Rodríguez de Fonseca F, Piomelli D (2000). Quantification of bioactive acylethanolamides in rat plasma by electrospray mass spectrometry. Anal Biochem 280: 87-93.

Glass M, Dragunow M, Faull RLM (1997). Cannabinoid receptors in the human brain: a detailed anatomical and quantitative autoradiographic study in the fetal, neonatal and adult human brain. Neuroscience 77: 299-318.

Gorriti MA, Rodríguez de Fonseca F, Navarro M, Palomo T (1999). Chronic (-)-delta9-tetrahydrocannabinol treatment induces sensitization to the psychomotor effects of amphetamine in rats. Eur J Pharmacol 365: 133-142.

Herkenham M, Lynn AB, Little MD, Johnson MR, Melvin LS, de Costa BR et al (1990). Cannabinoid receptor localization in brain. Proc Natl Acad Sci USA 87: 1932-1936.

Horrobin DF (1998). The membrane phospholipid hypothesis as a biochemical basis for the neurodevelopmental concept of schizophrenia. Schizophr Res 30: 193-208.

Kay SR, Fiszbein A, Opler LA (1987). The positive and negative syndrome scale (PANSS). Schizophr Bull 13: 261-276.

Kovasznay B, Fleischer J, Tanenberg-Karant M, Jandorf L, Miller $\mathrm{AD}$, Bromet E (1997). Substance use disorder and the early course of illness in schizophrenia and affective psychosis. Schizophr Bull 23: 195-201.

Leweke FM, Giuffrida A, Wurster U, Emrich HM, Piomelli D (1999b). Elevated endogenous cannabinoids in schizophrenia. NeuroReport 10: 1665-1669.

Leweke FM, Schneider U, Thies M, Münte TF, Emrich HM (1999a). Effects of synthetic delta9-tetrahydrocannabinol on binocular depth inversion of natural and artificial objects in man. Psychopharmacology 142: 230-235.

Linszen DH, Dingemans PM, Lenior ME (1994). Cannabis abuse and the course of recent-onset schizophrenic disorders. Arch Gen Psychiatry 51: 273-279.

Matsuda LA, Bonner TI, Lolait SJ (1993). Localization of cannabinoid receptor mRNA in rat brain. J Comp Neurol 327: $535-550$.

Meltzer HY (1999). The role of serotonin in antipsychotic drug action. Neuropsychopharmacology 21: 106S-115S.

Meyer-Lindenberg A, Miletich RS, Kohn PD, Esposito G, Carson RE, Quarantelli M et al (2002). Reduced prefrontal activity predicts exaggerated striatal dopaminergic function in schizophrenia. Nat Neurosci 5: 267-271.

Piomelli D (2003). The molecular logic of endocannabinoid signaling. Nat Rev Neurosci 4: 873-882. 
Rodríguez de Fonseca F, Navarro M, Gómez R, Escuredo L, Nava F, $\mathrm{Fu} \mathrm{J}$ et al (2001). An anorexic lipid mediator regulated by feeding. Nature 414: 209-212.

Semple DM, Ramsden F, McIntosh AM (2003). Reduced binocular depth inversion in regular cannabis users. Pharmacol Biochem Behav 75: 789-793.

Sim-Selley LJ, Martin BR (2002). Effect of chronic administration of $R$-(+)-[2,3-dihydro-5-methyl-3-[(morpholinyl)methyl]pyrrolo[1,2, 3-de]-1,4-benzoxazinyl]-(1-naphtalenyl)methanone mesylate (WIN55, 212-2) or delta(9)-tetrahydrocannabinol on cannabinoid receptor adaptation in mice. J Pharmacol Exp Ther 303: 36-44.

Ujike H, Takaki M, Nakata K, Tanaka Y, Takeda T, Kodama M et al (2002). CNR1, central cannabinoid receptor gene, associated with susceptibility to hebephrenic schizophrenia. Mol Psychiatry 7: 515-518.

Voruganti LNP, Slomka P, Zabel P, Mattar A, Awad AG (2001). Cannabis induced dopamine release: an in-vivo SPECT study. Psychiatry Res: Neuroimaging Sect 107: 173-177.

Yao JK, van Kammen DP, Reddy RD, Keshavan MS, Schmid PC, Berdyshev EV et al (2002). Elevated endocannabinoids in plasma from patients with schizophrenia. Biol Psychiatry 51: 64S-65S. 